\title{
SITUACIÓN ACTUAL DE COSECHA Y POST COSECHA DE CAFÉ EN LAS SEGOVIAS. NICARAGUA
}

Luis María Dicovskiy Riobóo Correo: luisdi@norte.uni.edu.ni Sub Director UNI Norte

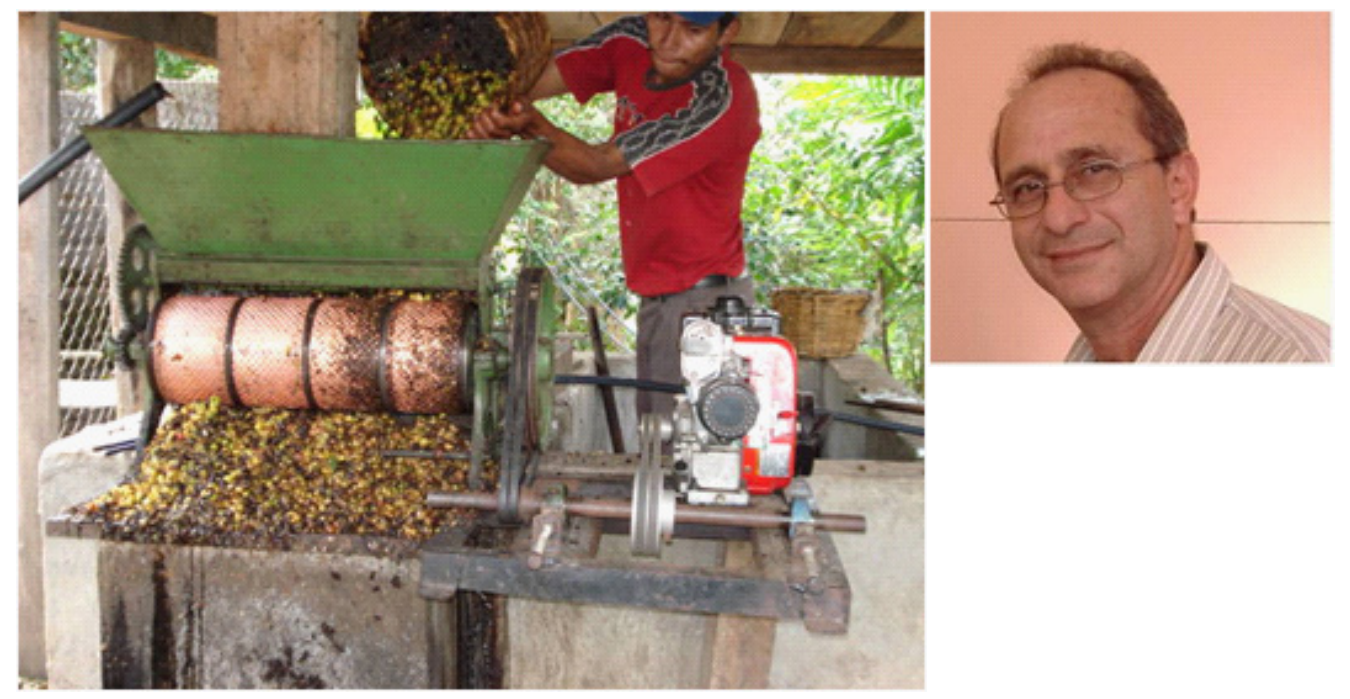

Despulpado de café

\section{RESUMEN}

Con el objetivo de caracterizar como se realiza la cosecha y poscosecha de café en las Segovias se hicieron 268 encuestas y muestras de catación a pequeños y medianos productores de café de las Segovias organizados en cooperativas. Se concluye que en la familia de los productores hay problemas de escolaridad lo que es una limitante para el desarrollo de sus sistemas de producción. La variedad de café Caturra es la predominante, y el café producido es de tipo especial. Todos cosechan a mano y fermentan el café. La mayoría de los productores tienen beneficios húmedos en su finca en un estado regular a malo. No se encontró efecto por altura de la finca, tipo de beneficio y horas de fermentación sobre la calidad de la taza de café. En general hay problemas con el manejo de los residuos del café y casi no se da uso al agua del despulpado, ni a las aguas mieles, sin embargo en general se usa la pulpa de café como abono.

\section{INTRODUCCIÓN}

Esta investigación fue financiada por la fundación FUNICA y coordinada por la UNI sede Estelí, en alianza con las organizaciones cooperativas de segundo nivel PRODECOOP y UCOSEMUN R.L., las cuales aglutinan a los pequeños y medianos productores de café de las Segovias, zona Norte Central de Nicaragua.

La información analizada surge de 268 encuestas. En orden de importancia, las encuestas se tomaron en los Departamentos de Nueva Segovia, Jinotega, Madriz y Estelí con productores pertenecientes a cooperativas asociadas a UCOSEMUN R.L. y PRODECOOP. Para contrastar las encuestas con la variable calidad de café, en las fincas encuestadas, se tomó muestras de café, las cuales luego de ser secadas se llevaron a catar.

\section{RESULTADOS ASPECTOS SOCIALES DE LAS FAMILIAS}

Las familias están conformadas por un promedio de 5.7 miembros. Puede afirmarse que son familias de jóvenes pues la mayoría se ubica entre las edades de 0 a 45 años y el promedio está en 25 años. Con relación al nivel educativo de las personas mayores de 12 años, la situación es bastante preocupante pues la mayoría tiene la primaria incompleta, pero cabe destacar que son pocos los analfabetos. No hay diferencias significativas entre hombres y mujeres.

Sigue existiendo una prevalencia de la división sexual del trabajo en el campo. Se reporta que la mayoría de las mujeres se dedican a las actividades domésticas en el hogar, pero un buen porcentaje de 
niñas, adolescentes y jóvenes estudian. Por la forma en que se estructuró la encuesta, no se revelen las actividades productivas que éstas realizan dentro de la casa o el apoyo que brindan en épocas pico de la cosecha del café. La mayoría de los hombres se dedican a las actividades agrícolas en su propia finca.

En cuanto a quienes se dedican a estudiar cabe destacar que hay una ligera diferencia a favor de los hombres, sin embargo se observa cierta equidad en cuanto a la oportunidad de fortalecer los conocimientos en educación formal.

Con relación a las viviendas en que habitan las familias, la mayoría ha logrado construir sus casas con techo de zinc (89\%) o teja (29\%), en orden descendente con paredes de adobe (58\%), cemento o madera y la mayoría vive en casa con pisos de tierra (54\%). Gozan de algunos servicios básicos tales como letrinas (91\%), agua potable (58\%) y electricidad (40\%). Viven 2.7 personas por habitación dormitorio. En general lo anterior indica que la mayoría de las viviendas son del tipo de familias pobres, pared de adobe, piso de tierra y letrina.

El hecho de tener electricidad ha dado a algunas familias la oportunidad de contar en su casa con televisor (38\%), la gran mayoría posee radio (83\%) y una minoría tiene teléfono (14\%). Este dato es importante pues se tienen posibilidades de llegar con mensajes a esta población principalmente a través de la radio.

\section{ASPECTOS DE LA PRODUCCIÓN}

La principal actividad productiva es el cultivo de café, $7 \mathrm{Mz}$. promedio. Las fincas tienen una media de 21.7 Mz., de éstas $13 \mathrm{Mz}$. son potreros y 9.4 Mz. de montaña, lo cual indica que aún hay espacios de conservación de biodiversidad silvestre, que hay que cuidar para que no sean eliminados con la extensión de los potreros. La mayoría reporta tener entre suficiente y bastante agua (81\%), la cual, en orden de importancia obtienen de ojos de agua (48\%), quebradas criques $(58 \%)$, pozos (3\%) y en un número poco significativo de ríos. La altitud promedio de las fincas estuvo en 1,129 msnm, y la mayoría de las fincas se encuentran entre 900 y 1350 msnm.

Las variedades de café utilizadas son Caturra (95\%), Bourbon (42\%), Catimor (26\%) y otras variedades no reportadas (44\%). La presencia de diferentes variedades de café es una oportunidad para que el país responda a la demanda de mezclas de café por parte de la industria. El 94\% de los productores hacen sus propios viveros lo cual redunda a favor de la disminución de los costos de producción pero esto puede estar afectando la calidad de los mismos, se deberían desarrollar viveristas especializados que usen semilla certificada y adecuado control de plagas.

Los que producen café convencional tienen de promedio145 quintales de café pergamino por finca, y los que producen orgánico 98 qq. La tecnología que está dando mayor producción de café por manzana es el café convencional con 22 qq pergamino $/ \mathrm{mz}$ ). El café orgánico está logrando promedios de 16 qq pergamino $/ \mathrm{mz}$. Habría que hacer costos para determinar si la menor producción compensa los mejores precios que este tipo de café logra en el mercado internacional. Por otro lado existe ausencia de una estrategia de consumo diferenciado en el mercado interno de este tipo de café.

El 97\% de los productores dicen que su principal fuente de ingreso es la venta de café, de éstos el 19.5 de los productores dicen vender su cosecha a futuro, el resto lo hace en la época tradicional de ventas. Aquí hay un espacio para crecer en este tipo de venta, que permite capitalizar al productor antes de tener la cosecha. El 94 $\%$ de los productores venden el café a las cooperativas en forma de café pergamino, poco se vende a los intermediarios o a casas comercializadoras, esto es un buen indicador de que la gente tiene confianza en sus organizaciones. Casi no se vende café en forma de oro, uva o pelota.

\section{BENEFICIADO, LAVADO, SECADO Y OREADO DEL CAFÉ}

El $75 \%$ de los encuestados dicen tener beneficio húmedo de café en su finca. Estos beneficios en su mayoría $(66 \%)$ tienen techo y un $46 \%$ tiene piso de cemento y 7 años promedio de ser construidos. El estado de los mismos según la apreciación de sus dueños es $50 \%$ regular, 33\% bueno y un 17\% malo. La ubicación de estos es principalmente a menos de 100 metros de las viviendas (72\%), ríos y quebradas $(29 \%)$, lo cual debe ser tomado en cuenta para las actividades dirigidas a prevenir la contaminación ambiental: alrededor de las viviendas para asegurar la salud de las familias y de 
ríos y quebradas para asegurar la calidad del agua.

Las despulpadoras más populares son las que usan pechera de hierro con camisa de bronce. De éstas el $94 \%$ tienen cilindro horizontal. Se manejan de forma manual el $58 \%$, con motor estacional el $41 \%$ y el $1 \%$ con energía eléctrica. Las despulpadoras se encuentran en buenas condiciones en un 56\%, regular 39\% y el resto en mal estado. Estos valores son algo mayor a lo que dice el estudio de PRONORCEN que solamente el 36.31 de las despulpadoras están en buen estado. La utilización por una minoría de despulpadoras con camisa de hule, $2 \%$, indica que esta tecnología que es menos agresiva al despulpar, no está siendo utilizada.

La fermentación del café se hace en un tiempo promedio de 16.3 horas, algo menor a las 22.6 horas reportadas por PRORNOCEN en el 2005. Sin embargo las frecuencias de horas más comunes son $12(24.7 \%)$ y 24 horas $(20.4 \%)$. El $83 \%$ de los productores no usan agua durante la fermentación, lo que acelera el proceso de la misma. Se debe verificar a campo de manera experimental el tiempo para llegar al punto óptimo. Los productores usan técnicas empíricas, sin embargo el tiempo puede variar por azúcares en el grano, capacidad de las pilas, dureza, pureza de aguas, tiempo entre corte y despulpado, etc. Datos de otros estudios indican que el tiempo promedio de fermentación varía entre 6 y 48 horas, en lugares más frescos dura un poco más (ANACAFE 2005). La fermentación se hace en canal de concreto (39\%), canal de madera (34\%), pila de concreto $(20 \%)$, cajón de madera $(11 \%)$ y el resto en canal de correteo. Los mismos datos se dan para el lavado del grano.

El secado y oreado del café se realiza en cajillas- zaranda $(89 \%)$, patios de concreto $(16 \%)$ y el resto se hace en plástico negro o patio de ladrillo, estos datos concuerdan con PRONORCEN que dice que el $82 \%$ de los productores usan cajillas. Esta labor tarda un promedio de 6 horas.

La minoría de los productores (5\%) está vendiendo servicio de beneficiado a sus vecinos. Aquí se presenta una oportunidad de construir beneficios entre varios productores y así compartir los costos de los equipos.

En la mayoría de las fincas se tarda a lo más 2 días entre el beneficio en finca y el acopio en el beneficio seco, lo lo que es valorado como un tiempo aceptable para que no se pierda calidad en el café.

\section{CALIDAD DEL CAFÉ}

Se hizo pruebas de catación utilizando las normas SCAA, siendo el valor promedio obtenido de 81 , que corresponde a un buen café especial, un buen sabor y acidez y un buen equilibrio. El $75 \%$ del café entró en esta categoría. Sin embargo el 35\% de las muestras tuvieron un valor menor a 80 , que lo sitúa a esta proporción como un café de "calidad justa". (Transfair USA, SOPPEXCA, 2007)

No se encontró correlación significativa entre altitud de las fincas y la calidad del café. Esto hace suponer que entre 900 y $1350 \mathrm{msnm}$, altura en que se encontraban la mayoría de las fincas, ésta no influyó en la calidad del café.

Tampoco se encontró correlación significativa entre "calidad" y "horas de fermentación del café". Sin embargo al agrupar la variable "horas de fermentación" en 3 grupos: 0 -10 horas, $+10-20$ horas, +20 horas, se encontró que los que fermentan menos de 10 horas tienen un café de calidad levemente inferior, 79 puntos, mientras que los que fermentan más de 10 horas tienen 82 puntos. Sin embargo esta observación debe ser tomada con precaución porque sólo había 8 casos en que se fermentaba menos de 10 horas, lo que pudo producir un sesgo por muestra pequeña.

Al tratar de encontrar relación con el tipo de beneficio y la calidad del café, no se encontró diferencias estadísticas usando pruebas " $\mathrm{t}$ " para muestras independientes entre las variables: "calidad" con "beneficios de piso de tierra o de concreto" y "calidad" con "beneficios techados ó no".

\section{MANEJO DE AGUAS}

El 99\% de los encuestados afirma que el agua que entra al beneficiado del café entra limpia y el $84 \%$ dice que la saca contaminada lo cual obliga a que se le dé tratamiento o se le busque un uso alternativo.

El 40\% dice manejarla en fosas de infiltración, el 15\% la deposita en lagunas artificiales, el 7\% en canales, el $7 \%$ a ríos o quebradas y el $5 \%$ la utiliza para riego. No 
se tienen datos si ese $7 \%$ que se encausa a ríos y quebradas sean del 15\% que los productores dicen sacar limpia, si no es así, implica que se está poniendo en peligro la vida de especies acuáticas y bajando la calidad de agua para consumo humano. El poco uso que se le está dando a las aguas mieles justifica el estudio que se realizará sobre su aprovechamiento.

El agua de despulpado el 70\% no la utiliza y sólo un 8\% la ocupa como abono foliar. El destino de las aguas de despulpado es lagunas de oxidación (24\%), pilas (4\%), fosas de concreto $(2 \%)$ y otras $(70 \%)$.

\section{MANEJO DE LA PULPA Y MUCÍLAGO.}

La pulpa es uno de los mayores contaminantes de las fuentes de agua. Esta es manejada por volteo (40\%), secado $(39 \%)$ y utilizada para lombricultura (13\%). Se esperaba un mayor uso de la lombricultura, ya que esta es una actividad que ha sido promocionada por las cooperativas. A la mayoría de la pulpa no se le hace ninguna aplicación de productos que disminuyan su volumen, malos olores o ambos (49\%), los que utilizan cal con la pulpa son el $31 \%$ y el $17 \%$ hace otro tipo de tratamientos. El 83\% de los productores aprovecha la pulpa para abono, el resto no la utiliza para nada, esta información es mejor que el $60 \%$ que informa PRONORCEN. En cuanto al mucílago sólo el $18.4 \%$ de los productores lo recoge. El mucílago no es utilizado por el $71 \%$ de los productores y el 13\% lo utiliza como abono foliar, aquí se presenta una oportunidad de investigación sobre cómo utilizar este subproducto.

\section{CONCLUSIONES}

Se concluye de manera general que:

\section{En la Familia}

- Hay equidad de género en la educación en las familias de productores.

- Hay roles diferenciados, la mujer hace tareas del hogar, el hombre tareas agrícolas.

- En mayores de 12 años, predomina el nivel de primaria incompleta, $39 \%$ lo que es una limitante para el desarrollo de sus sistemas de producción.

-Predomina la gente joven, lo que es una oportunidad a futuro.

\section{Los aspectos productivos y de poscosecha relevan- tes son que}

- Se reconoce que el café es la principal actividad económica.

- La variedad Caturra es la variedad que predomina.

- Todos cosechan manualmente y fermentan el grano de café para retirar el mucílago de la semilla.

- La mayoría de los productores tiene beneficios húmedos en la finca y estos están en un estado que varía entre regular y malo.

- Casi no se usa electricidad como fuerza motriz del beneficio húmedo

- La mayoría de los beneficios tiene agua abundante o suficiente para realizar el beneficio húmedo en finca.

- La mayoría tarda 2 días desde que beneficia en finca, hasta el acopio en los beneficios secos, propiedad de empresas privadas o de las cooperativas, allí es donde se seca el café hasta el12\% de humedad.

\section{Referente a la calidad del café}

-El café que producen estas fincas es en su mayoría de tipo especial.

- Al buscar correlaciones vinculantes con la calidad, no se encontró efecto por altura de la finca, tipo de beneficio y horas de fermentación sobre la calidad del café.

\section{Sobre el manejo de los Residuos}

Se observan algunos problemas en las fincas al momento de beneficiar, tales como que:

- El 76 \% no usa el agua del despulpado de la semilla.

- El 83 \% usa la pulpa producto del beneficiado como abono.

- El $49 \%$ no le aplica nada a la pulpa para reciclarla.

- El 82 \% no recoge el mucílago producido por el fermentado.

- El $71 \%$ no da ningún uso al mucílago

- E1 84 \% reconoce que el agua que sale del beneficio está contaminada, pero la recibe limpia, $99 \%$.

\section{CONSULTAS}

- ANACAFE. (2005) Manual del Beneficiado Húmedo. Guatemala. $250 \mathrm{pp}$.

- PRONORCEN. (2005). Identificación de fincas cafetaleras con calidad de altura. Nicaragua.

- Transfair USA, SOPPEXCA. (2007). Guía de 1Mercado del Café de Estados Unidos. 